\title{
A model of enterprise integration and collaboration tools and communication infrastructure for inter-enterprise collaboration $^{\dagger}$
}

\author{
Z. Deng, B. Bang, A. Lakså, and S. Nadarajah \\ Narvik Institute of Technology \\ Lodve Langes gt. $2 \bullet 8501$ Narvik $\bullet$ Norway \\ Tel: (47) 76966000 • Fax: (47) 76966810 \\ E-mail:vm-grp@hin.no
}

\begin{abstract}
This paper first discusses a model of enterprise integration that consists of a micro level, a midcro level, and a macro level integration. Secondly, the architecture for midcro inter-enterprise integration is composed consisting of three layers, a communication layer, a collaboration layer, and an application layer. To the collaboration layer, synchronous and asynchronous collaborations are discussed and a toolkit for those collaborations is studied and assembled. Then to the communication layer, a communication infrastructure for a research test-bed and a project for midcro inter-enterprise integration is described.
\end{abstract}

Keywords

Enterprise integration, system modeling, virtual manufacturing, communication, infrastructure, collaboration

\section{INTRODUCTION}

Since computer integrated manufacturing (CIM) concept raised late 1960s, the topic of enterprise integration has been explored for three decades. Conventionally, CIM is mostly concerned with intra-enterprise integration, i.e. integration within a given enterprise.

Today, manufacturing enterprises are faced with challenges globally. Increasingly, these challenges cannot be effectively met by isolated effort within a single enterprise. Therefore, enterprise integration is nowadays concerning with 
not only what happens within a given enterprise (intra-enterprise integration), but also what happens among a group of enterprises (inter-enterprise integration).

From such a reality, it is necessary to study first how many types of enterprise integration exist that are necessary to be studied for meeting the challenge. For this purpose, a three-level model of enterprise integration is conceived that consists of a micro level, a midcro level, and a macro level integration (see Figure 1). We work mainly at the midcro enterprise integration involving in the integration among a group of enterprises including a host enterprise, a chain of supply enterprises, and a chain of selling agencies. (Deng, 1997).

\section{A THREE LEVEL MODEL ON ENTERPRISE INTEGRATION}

As shown in Figure 1, those three levels can be described as follows:

- Micro integration is internal behavior-optimization centered integration within a single enterprise (intra-enterprise integration). In the case of a productiontype enterprise, it involves in the integration among management division (m), engineering division (e), and shopfloor (sf) as shown in the lower left of Figure 1. In the case of a service-type enterprise (selling agency), it involves in the integration among management division (m), selling division (sl), and service division (sv) as shown in the lower right of Figure 1.

- Midcro integration is product-alliance-centered integration among a group of enterprises. This class of integration involves in a host enterprise integrated with enterprises in the supply-chain and distribution-chain for their common products as shown in upper two ovals of Figure 1. In this figure, the hierarchy of supply-chain is depicted to contain first-tier, second-tier, and third-tier of supply enterprises; the distribution-chain is depicted to contain two tiers of hierarchy. They can be composed of more tiers down the chains. In the book written by Miyashita (1996), the midcro integration is called a vertical Keiretsu.

- Macro integration is a finance-alliance and risk reduction centered integration. As shown in the upper oval of Figure 1, all members in the macro integration group are host enterprises (denoted as $\mathrm{H}$ ). Each of them possesses its own supply and distribution chains (in Figure 1, only one host enterprise is depicted to show its supply and distribution chains down into the middle oval). The only exception is a special enterprise - financial organization (denoted as F, such as a bank which is depicted in the middle of the upper oval of Figure 1). The products of those host enterprises vary greatly from enterprise to enterprise such as vehicles, steel, electronics, warehouse, insurance, etc. In the book written by Miyashita (1996), such integration is called a horizontal Keiretsu.

In summary, the micro integration falls into the class of intra-enterprise integration, and both midcro integration and macro integration fall into the class of inter-enterprise integration. 


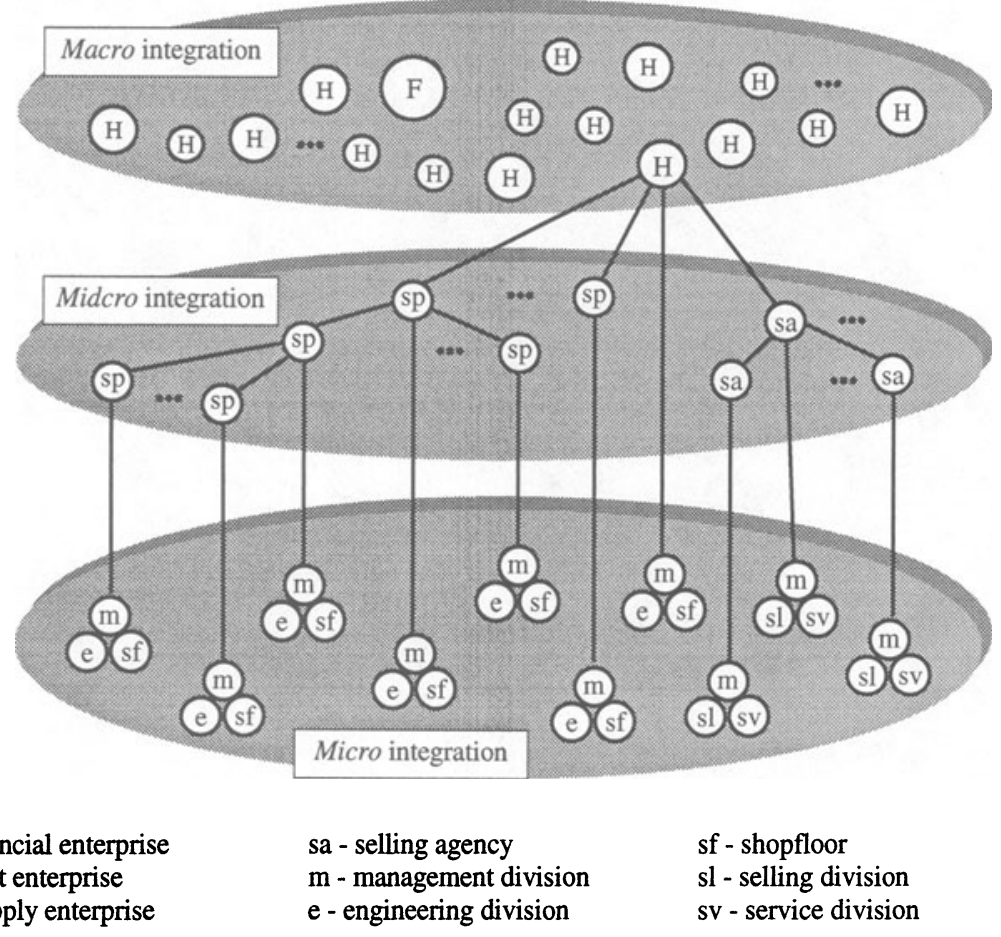

Figure 1 A three level model on enterprise integration.

Industries in Northern Norway are widely dispersed. Their supply and distribution chains are rather dispersed and even globally dispersed. For example, the supply chain and distribution chain of Fundia Bygg AS, a metallurgy company in Mo i Rana, Northern Norway is dispersed across Scandinavian and Central European countries. The LKAB Logistics Narvik Ore Harbor in Narvik, Northern Norway has its supply chain and distribution chain dispersed across Scandinavian, Central European, and even Asian countries. Therefore, our main concern is to create an advanced research test-bed for industries in Northern Norway (ART_INN) on midcro inter-enterprise integration. And based on the support of ART_INN, promote joint ventures with and provide services for industries in Northern Norway under a project called virtual manufacturing (dynamic midcro inter-enterprise integration) for industries in Northern Norway (VM_INN). In the following sections, we shall call the midcro inter-enterprise integration as interenterprise integration for brevity.

There exist workflow, information flow, material flow, and fund flow among the host enterprise, supply enterprises, and the selling agencies. In this paper, we focus on the workflow and information flow, i.e. on the problems of how to aid the workflow and information flow among enterprises effectively and efficiently. 


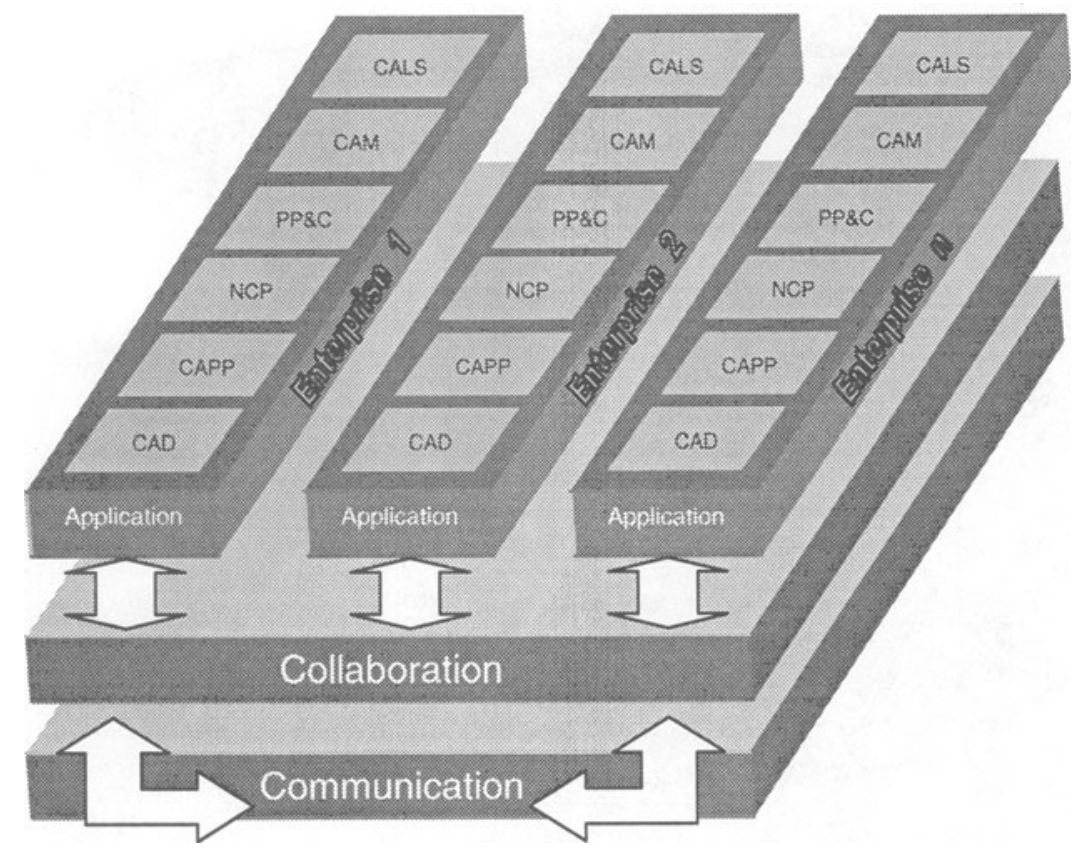

Figure 2 Architecture for midcro inter-enterprise integration.

\section{AN ARCHITECTURE FOR INTER-ENTERPRISE INTEGRATION}

There is need to have an overview (architecture) of the workflow and information flow among enterprises before we can go into details. It is shown in Figure 2.

To realize the workflow and information flow among the enterprises, obviously, they must be able to communicate with each other. Thus a communication infrastructure is the basic necessity as shown in the lower part of Figure 2 where it is depicted as a layer called communication.

Based on the support from the communication infrastructure, the collaborative tasks can be as follows (refer to upper part of Figure 2):

- Collaborative product design by means of computer aided design (CAD) application,

- Collaborative process planning and numerically controlled programming (NCP) by means of computer aided process planning (CAPP) and computer aided NCP applications,

- Collaborative production planning and control (PP\&C) by means of computer aided PP\&C application,

- Collaborative manufacturing via remote control of manufacturing cells and workstations by means of computer aided manufacturing (CAM) applications,

- Collaborative logistics management by means of a computer aided logistics system (CALS),

- etc. 
As shown in the upper part of Figure 2, those applications (CAD, CAPP, etc.) reside in the application layer. They can be installed and run in every enterprise.

To enable collaborative tasks (design, planning, etc) among enterprises, the communication layer serves to run the information flow among enterprises. However, to attain more effective collaboration, we need also collaboration tools to aid a better workflow among enterprises. Those tools reside in the collaboration layer as shown in the middle of Figure 2.

\section{SYNCHRONOUS AND ASYNCHRONOUS COLLABORATION}

The workflow among enterprises can be categorized into synchronous collaboration and asynchronous collaboration.

Synchronous collaboration means that geographically dispersed partners are working in an on-line mode. They are working collaboratively at different locations but at same time. In some cases, it is called a meeting or a conference. Thus, we need a tool to realize the synchronous collaboration (see lower left of Figure 3). By means of this tool, the partners can see each other via video display on the screens, talk with each other via audio phones, exchange ideas via text chat or white board on the screens, and share the applications (CAD, CAPP, NCP, PP\&C, CAM, CALS, etc) on the screens.

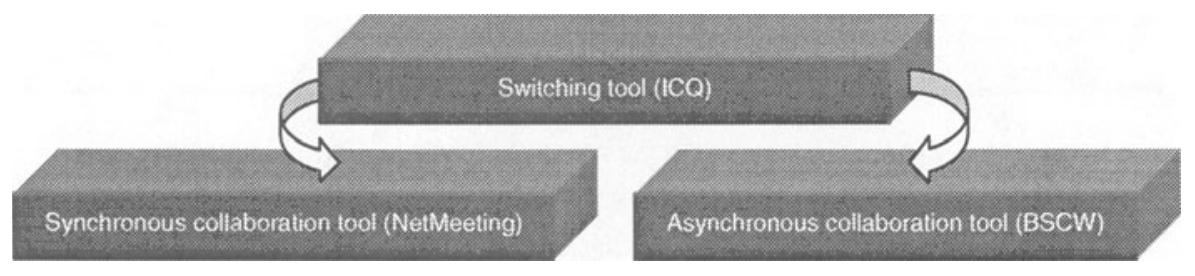

Figure 3 Relationship between synchronous, asynchronous, and switching tools.

Asynchronous collaboration means that the collaborative partners work in an off-line mode, i.e. the partners do not work at the same time. In many cases, the off-line working mode is much preferable, because different people may have different time schedule in daily work and it is difficult to find a commonly agreed period to have a meeting. In such cases, they will preferably work in the asynchronous collaboration mode. Thus, we need another tool to realize the asynchronous collaboration (see lower right of Figure 3). By means of this tool, one can work alone, for example, design a product alone by a CAD application. After one has completed the design, s/he stores her/his file in some shareable location (server), then send a message to inform other partner asking her/him to fetch the design data from the shareable location for further working (comment or modification). After further working, the partner, in turn, stores the resulting file into the shareable location, and send a feedback message to the original designer informing her/him that a comment or a modification has been done.

Certainly, after certain interactions of asynchronous working, for making important decisions, it may require to have a synchronous meeting. Thus, we need 
a third tool to realize the switching between synchronous working and asynchronous working (see upper part of Figure 3).

To summarize, in addition to the support from communication layer, we need a collaboration toolkit that includes three tools, one synchronous collaboration tool, one asynchronous collaboration tool, and one switching tool to aid the interenterprise integration. This toolkit resides in the collaboration layer at the middle of Figure 2. The relationship among the three tools is depicted in Figure 3.

\begin{tabular}{|c|c|c|c|}
\hline Functions & $\begin{array}{c}\text { Microsoft } \\
\text { NetMeeting (v2.0) } \\
\text { (O'Donnell, 1997) }\end{array}$ & $\begin{array}{c}\text { Netscape } \\
\text { Conference (V4.0) } \\
\text { (James, 1997) }\end{array}$ & $\begin{array}{c}\text { Cu-SeeMe } \\
\text { (V0.92b2) } \\
\text { (Cu-SeeMe, 1998) }\end{array}$ \\
\hline Audio chat & $x$ & $x$ & $x$ \\
\hline Text chat & $\ddot{x}$ & $x$ & $x$ \\
\hline Video conferencing & $\hat{x}$ & & $\hat{x}$ \\
\hline Application sharing & $x$ & & \\
\hline Collaborative browsing & & $\mathrm{x}$ & \\
\hline Whiteboarding & $\mathrm{x}$ & $\hat{x}$ & \\
\hline File transfer & $\hat{x}$ & $\hat{x}$ & \\
\hline $\begin{array}{l}\text { Audio and video bandwidth } \\
\text { consulting }\end{array}$ & $\mathrm{x}$ & & $\mathrm{x}$ \\
\hline Security zone & $\mathrm{X}$ & $\mathrm{X}$ & \\
\hline Digital certificate & $\mathrm{x}$ & $\mathrm{x}$ & \\
\hline Connecting Proxy server & $\hat{x}$ & $x$ & \\
\hline Enabling security protocol & $x$ & $x$ & \\
\hline
\end{tabular}

\section{EXAMINATION AND ASSEMBLY OF COLLABORATION TOOLKIT}

Many collaboration tools exist in the market nowadays. It is necessary to have a survey and examination to find the right tools for meeting the requirements of inter-enterprise integration.

\subsection{Tool for synchronous collaboration}

For meeting the requirements of synchronous collaboration, some of popular tools for synchronous collaboration such as Microsoft NetMeeting, Netscape Conference, and $\mathrm{Cu}$-SeeMe are evaluated. Their functions are listed in Table 1.

The most important function for a synchronous collaboration tool for interenterprise collaboration is application sharing. In other words, it must be able to execute collaborative CAD, CAPP, PP\&C, etc. applications among enterprises simultaneously. 


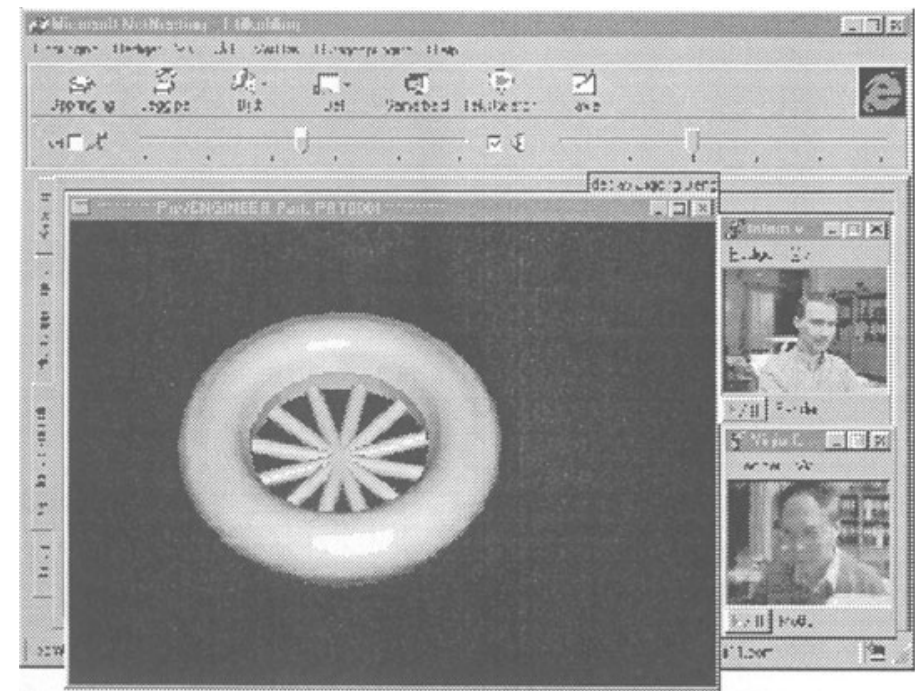

Figure 4 Screen display at collaboration launcher side.

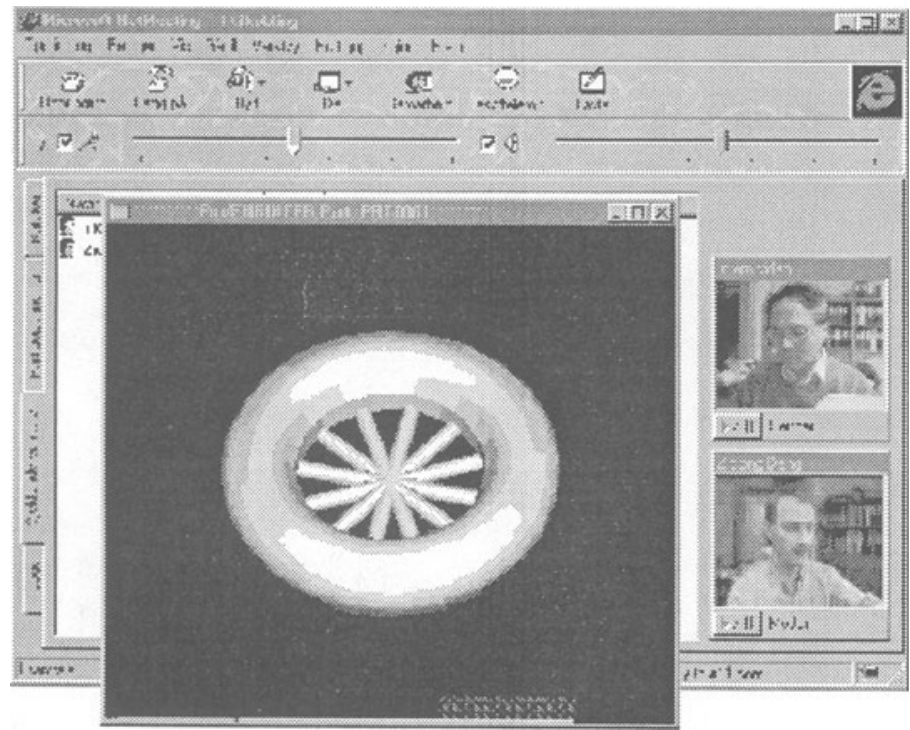

Figure 5 Screen display at collaboration partner side.

For instance, when one launches a collaborative design meeting for a product, a $\mathrm{CAD}$ application should first run at one's own computer. At the same time, the $\mathrm{CAD}$ design can be shared among the geographically dispersed partners, i.e. the graphics of the product being displayed on the launcher's screen should 
simultaneously appear on screens of all partners. Based on such a simultaneous displaying, the partners can take part in the discussions to comment the design via audio chat, text chat, and white board drawing. Meanwhile, they can see each other on the screen. Furthermore, if the launcher wants the partners to directly modify the design on the screen instead of only to comment the design, it should be able to do so. Again, when they deem that there is need to keep their information in secret, the tool should be able to provide necessary security functions for information exchanging.

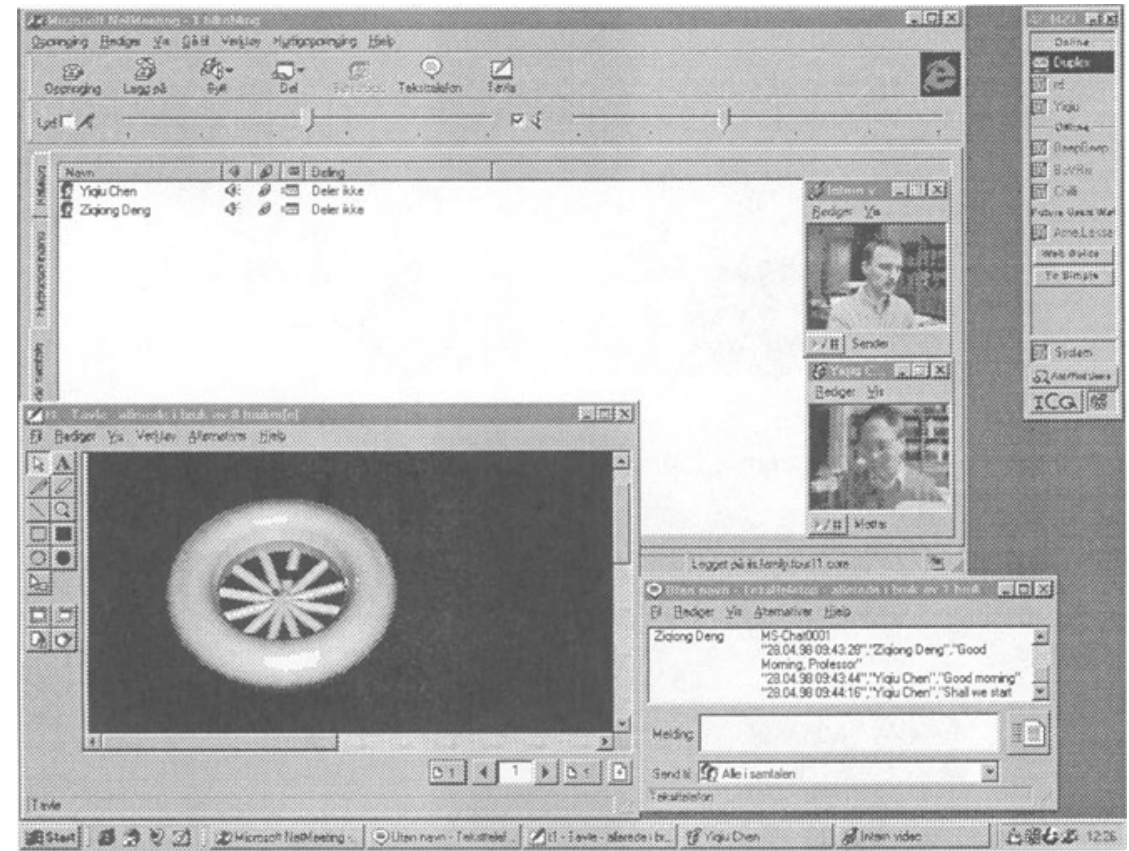

Figure 6 Text chat window and white board window from NetMeeting.

We have experimented with those tools listed in Table 1. From there, we find that the Microsoft NetMeeting is the only tool being able of providing the application sharing function. So we choose it as our synchronous collaboration tool.

Figures 4 and 5 show the screen displays of Microsoft NetMeeting at the launcher side and partner side where a CAD application, ProEngineer, is running at the launcher side and is being shared by the partner. As shown in the right parts of these figures, the launcher and the partner can see each other via video pictures. As well, they can talk with each other via microphones and speakers (at the upper parts of Figures 4 and 5, the output adjusters of microphones and speakers are shown). They can use text chat and/or white board drawing for discussion as well. 
The lower right part of Figure 6 shows the text chat window and lower left part of Figure 6 shows the white board window.

\subsection{Tool for asynchronous collaboration}

The requirements to the tool for asynchronous collaboration have been discussed in section 4. This tool should be able of:

- Storing documents in a shareable workplace,

- Providing a server by the vendor and creating a server by users themselves,

- Collaborative editing,

- Controlling the degree of sharing,

- Tracking the workflow such as event and activity notification and version management,

- Controlling the security such as access right control, member administration, and encryption.

\section{Table 2 Selected functions of popular tools for asynchronous collaboration}

\begin{tabular}{|c|c|c|c|c|}
\hline & Functions & $\begin{array}{c}\text { BSCW } \\
\text { (Bentley, 1997) }\end{array}$ & $\begin{array}{c}\text { Lotus Notes \& } \\
\text { Domino } \\
\text { (Kreisle, 1997) }\end{array}$ & $\begin{array}{c}\text { WebBoard } \\
\text { (WebBoard, } \\
\text { 1998) }\end{array}$ \\
\hline Shareable & Fully user-owned & $\mathrm{x}$ & & \\
\hline workplace & Partially user-owned & & $\mathrm{x}$ & $\mathrm{x}$ \\
\hline & Vender server available & $\mathrm{x}$ & $\mathrm{X}$ & $\mathrm{X}$ \\
\hline Server & User own server createable & $\mathrm{x}$ & & \\
\hline Network & Mainly Internet based & $\mathrm{x}$ & & $\mathrm{x}$ \\
\hline & Mainly Intranet based & & $\mathrm{x}$ & \\
\hline & Event \& activity notification & $\mathrm{X}$ & $\mathrm{X}$ & $\mathrm{X}$ \\
\hline Iracking & Version management & $\mathrm{x}$ & $\mathrm{x}$ & $\mathrm{x}$ \\
\hline Collaborati & editing & $\mathrm{X}$ & $\mathrm{X}$ & $\mathrm{X}$ \\
\hline Degree of : & aring control & $\bar{x}$ & $\mathrm{x}$ & \\
\hline Security & Access right control & $\mathrm{X}$ & $\mathrm{X}$ & $\mathrm{X}$ \\
\hline & Member administration & $\mathrm{x}$ & $\mathrm{x}$ & $\mathrm{x}$ \\
\hline
\end{tabular}

For meeting those requirements, some of the popular tools such as BSCW (Basic Support for Cooperative Work), Lotus Notes and Domino, and WebBoard are evaluated. Their functions related to the requirements mentioned above are listed in Table 2.

We have experimented with tools listed in Table 2. From there, we find that the BSCW tool is more suitable for the purpose of asynchronous inter-enterprise collaboration. First, the BSCW vendor provides a central server where the users can have a full right to create and own their shareable workplaces. Second, it also provides a downloadable program to aid the users to create their own BSCW servers when necessary. And third, the BSCW is Internet based. Those features are much preferable in virtual manufacturing (dynamic re-organization) environment.

Figure 7 shows a BSCW page displaying the shared folders and files in where the information of collaborative editing, event notification, version management, etc. are shown. Figure 8 shows the information related to the BSCW access control function. 


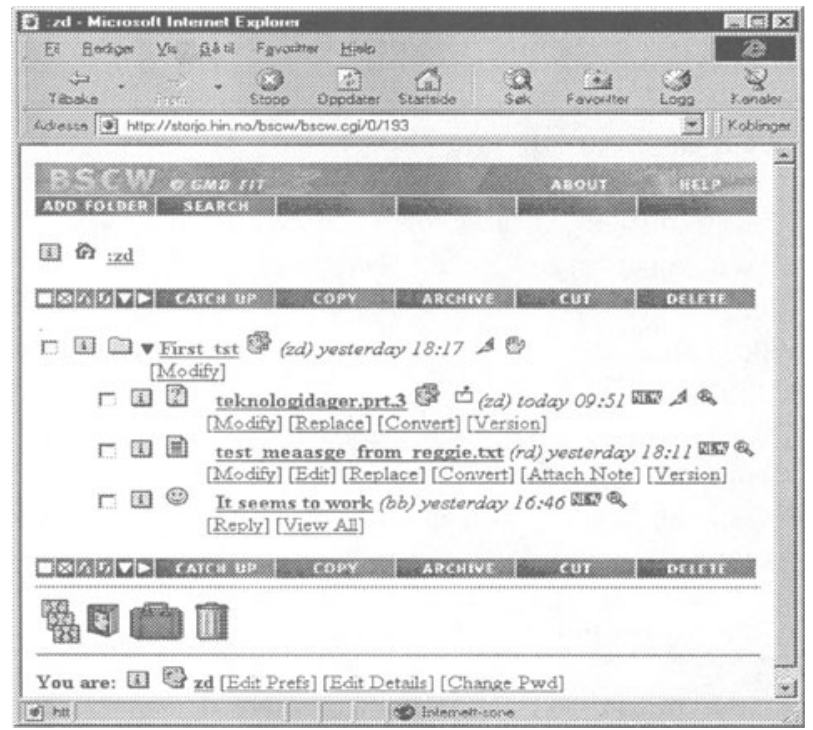

Figure 7 A BSCW page displaying the shared folder and files.

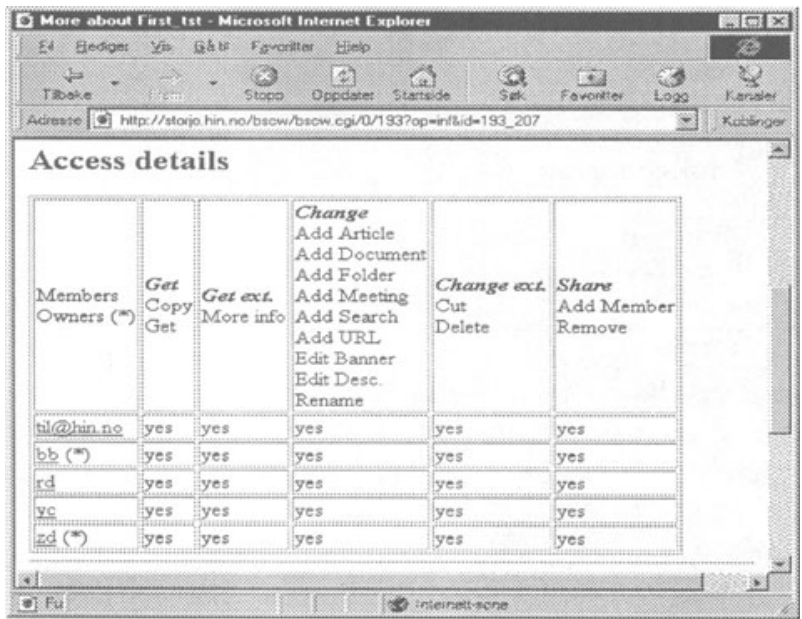

Figure 8 A BSCW shared workspace is defined to be shared among five members. 


\subsection{Tool for switching between synchronous collaboration and asynchronous collaboration}

A switching tool should be able of:

- Working in the background quietly all the time whenever one turns on her/his computer, no matter s/he is working on any other program or in idle,

- Popping up a blinking symbol and/or an alerting sound from the background to indicate that a switching message has come, no matter the local computer is on or off when the message is coming,

- Displaying the collaborative partners to indicate if they are online or offline at real-time,

- Sending offline message to a partner, no matter the partner is turning her/his computer on or off at this moment,

- Online chatting with other partners for negotiating a synchronous or asynchronous collaboration or other relative matters.

We have experimented with those tools listed in Table 3. We choose the ICQ as our switching tool. This is because in our case we need not only the online switching function, but also "offline and pop-up" switching function.

\section{Table 3 Selected functions of popular tools for switching}

\begin{tabular}{|c|c|c|c|c|}
\hline & Functions & $\begin{array}{c}\text { ICQ } \\
\text { (Mirabilis } \\
\text { LTD, 1998) }\end{array}$ & $\begin{array}{c}\mathrm{AOL} \\
(\mathrm{AOL}, 1998)\end{array}$ & $\begin{array}{c}\text { Conven- } \\
\text { tional } \\
\text { E-mail }\end{array}$ \\
\hline Waiting g & etly in the background & $\bar{x}$ & $\bar{x}$ & $\mathrm{X}$ \\
\hline & $\begin{array}{l}\text { Pop-up in condition of both sides } \\
\text { online }\end{array}$ & $x$ & $x$ & \\
\hline Recetve & $\begin{array}{l}\text { Pop-up despite of the local } \\
\text { computer online/offline previously }\end{array}$ & $\mathrm{x}$ & & $\mathrm{X}$ \\
\hline & $\begin{array}{l}\text { Display partners' online/offline } \\
\text { information on desktop }\end{array}$ & $\mathrm{X}$ & $\mathrm{x}$ & \\
\hline Send & Offline message to partners & $\mathrm{X}$ & & $\mathrm{X}$ \\
\hline & Online chat & $\mathrm{x}$ & $\mathrm{x}$ & \\
\hline
\end{tabular}

At the lower right corner of Figure 6, the ICQ icon is shown. It indicates that the ICQ program is sitting in the background. At the right part of Figure 6, the ICQ front window shows the partners' online, offline, ... information.

To summarize, from section 5.1 through 5.3, the collaboration toolkit is studied and assembled for our inter-enterprise collaboration purpose. It contains the ICQ tool, NetMeeting tool, and BSCW tool as shown in Figure 3

\section{COMMUNICATION INFRASTRUCTURE FOR VM_INN}

Refer back to Figure 2, we have discussed the collaboration layer in sections 4 and 5. This section comes to discuss the communication layer, i.e. to discuss the communication infrastructure for our VM_INN project.

The communication layer for VM_INN should be able of: 
- Evaluating various alternatives of inter-enterprise communications such as LAN (local area network) - Internet - LAN, LAN - ISDN (integrated service digital network) - LAN, Intranet - Internet - LAN, Intranet - ISDN - LAN, etc,

- Studying the efficiency, security, and cost effectiveness on various

communication alternatives

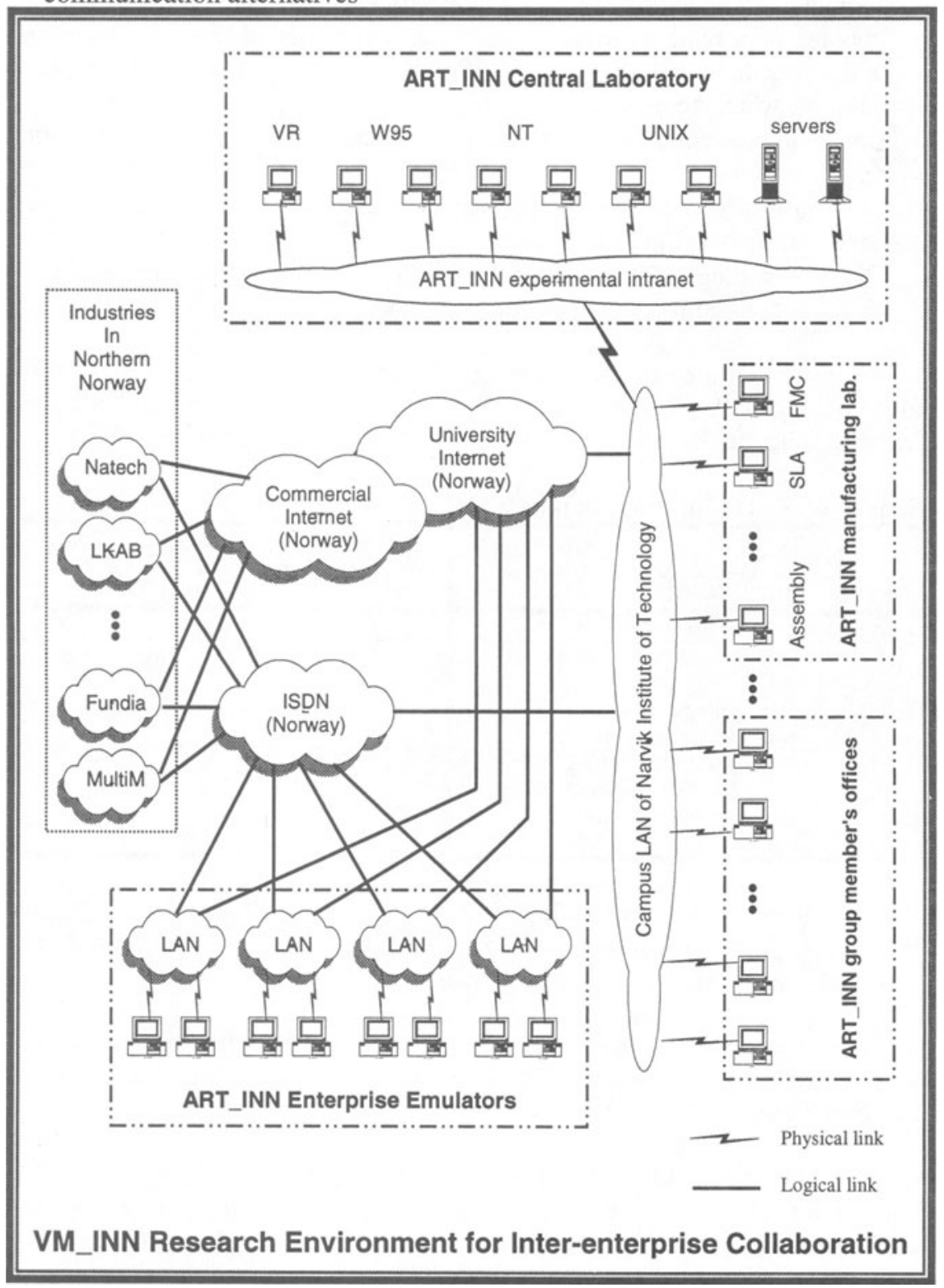

Figure 9 Current configuration of communication infrastructure for VM_INN. 
- Experimenting multi-media communication,

- Testing portable and wireless communication, and new communication technologies such ATM, B-ISDN, etc.

Figure 9 shows the current configuration of communication infrastructure for the VM_INN. The environment consists of five parts. One is the ART_INN central laboratory (top of Figure 9) where the preliminary research on inter-enterprise collaboration can be carried out based on multi platforms within the Intranet. The servers serve for collaborations not only for central laboratory itself, but also for other four parts. They are (1) ART_INN group member's offices (lower right of Figure 9), (2) ART_INN manufacturing laboratory (upper right of Figure 9), (3) ART_INN enterprise emulators (bottom of Figure 9), and (4) industries in Northern Norway (left of Figure 9).

The ART_INN central laboratory can communicate with the ART_INN group member's offices to experiment collaborations within the campus. Further, the experiments can be extended beyond the campus to the ART_INN enterprise emulators that are dispersed in the suburb of Narvik and Trodheim, $930 \mathrm{~km}$ south of Narvik.

Furthermore, the ART_INN central laboratory, the ART_INN group member's offices, and/or the ART_INN enterprise emulators can execute the collaborations with the industries in Northern Norway (left of Figure 9). And the industries in Northern Norway can collaborate with each other and/or invoke the resource support from servers in the ART_INN central laboratory.

The remote control of collaborative manufacturing can be executed either between the ART_INN manufacturing laboratory and the other four parts, or among industries in Northern Norway.

The University Internet (Norway), the Commercial Internet (Norway), and the ISDN (Norway) shown in the middle of Figure 9 support all those communication activities.

\section{CONCLUSION}

As the discussion above, this paper focuses on the problems of how to aid the enterprise integration for industries in Northern Norway. The research on this topic is being supported and funded by Norwegian Research Council (NFR) since the beginning of 1998. This paper explains the first phase work of this project. It starts with a study on a three-level model of enterprise integration and considering the real environment of industries in Northern Norway; a conclusion is attained that we should concentrate efforts in the midcro inter-enterprise collaboration.

For working in the midcro inter-enterprise collaboration, it is necessary to have a general framework (architecture) to overview this project. A three-layer architecture is, therefore, conceived consisting of a communication layer, a collaboration layer, and an application layer.

For the collaboration layer, a detail study on assembling a toolkit to aid the synchronous and asynchronous collaborations has been carried out. In the next 
research phase, we think it is necessary to further study the coordination methodologies and tools in addition to the collaboration layer.

For the communication layer, this paper introduces the current consideration and configuration on the communication infrastructure of the VM_INN. In the next research phase, we think it is necessary to experiment various alternatives of interenterprise communications such as LAN - Internet - LAN, LAN - ISDN - LAN, Intranet - Internet - LAN, Intranet - ISDN - LAN, etc. And study the efficiency, security, and cost effectiveness on various communication alternatives.

For the application layer, we think it is necessary to further study and assemble application toolkits for various classes of enterprises such as machinery class, ore harbor logistic class, metallurgy class, etc.

\section{ACKNOWLEDGEMENT}

The authors would extend their sincere thanks to Stig-Roland Knutsen, Sidsel Kruuse-Meyer, and Ellen M. Julin for their effective help in preparing this paper.

\section{REFERENCES}

AOL (1998) Quick Tips for Getting Started, http://www.aim.aol.com/netscape/quicktips.html.

Appelt, W. and Busbach, U. (1996) The BSCW System: A WWW-Based Application to Support Cooperation of Distributed Groups, in Proceedings of the fifth Workshops on Enabling Technologies: Infrastructure for Collaborative Enterprises WET ICE '96, Stanford, IEEE Computer Press.

Bentley, B. et al (1997) Basic Support for Cooperative Work on the World Wide Web, International Journal of Human Computer Studies: Special issue on Novel Applications of the WWW, Academic Press, Cambridge.

$\mathrm{Cu}-\mathrm{SeeMe}$ (1998) Introduction, http://cu-seeme.cornell.edu/V32X/introduction.html.

Deng, Z. (1997) A Model of Methodology Need for AQAL Production System, Re-engineering for Sustainable Industrial Production, Chapman \& Hall, ISBN 0-412-79950-2.

James, P. and Andreessen, M. (1997) Netscape Communicator 4, Basic Books, Ventana, ISBN 1-56604-618-1.

Kreisle, B. (1997) Lotus Notes 4.5: Covers Domino 4.5, Basic Books, MIS:Press, ISBN 1-55828-529-6.

Mirabilis LTD (1998), Entry Level Guide - ICQ Starter, http://www.icq.com/icqtour/new-quicktour.html.

Miyashita, K. and Russell, D. (1996) Keiretsu - Inside the Hidden Japanese Conglomerates, Basic Books, McGraw-Hill.

O'Donnell, J. and Ladd, E. (1997) Using MICROSOFT Internet Explorer 4, Basic Books, Que Corporation, ISBN 0-7897-1046-3.

WebBoard (1998) WebBoard 3.0 - Product Information, http://www.webboard.oreilly.com/wb3/product_info/features_main.html. 